\title{
Corticosteroids for treatment of sore throat: systematic review and meta-analysis of randomised trials
}

\author{
Behnam Sadeghirad, ${ }^{1,2}$ Reed A C Siemieniuk, ${ }^{1}$ Romina Brignardello-Petersen, ${ }^{1,3}$ Davide Papola, ${ }^{4}$ \\ Lyubov Lytvyn, ${ }^{5}$ Per Olav Vandvik, ${ }^{6,7}$ Arnaud Merglen, ${ }^{8}$ Gordon H Guyatt, ${ }^{1}$ Thomas Agoritsas ${ }^{1,9}$
}

$\overline{{ }^{1} \text { Department of Health Research }}$ Methods, Evidence, and Impact (HEI), McMaster University, Hamilton, ON, Canada

${ }^{2}$ HIV/STI Surveillance Research Centre, and WHO Collaborating Centre for HIV Surveillance, Institute for Futures Studies in Health, Kerman University of Medical Sciences, Kerman, Iran ${ }^{3}$ Faculty of Dentistry, University of Chile, Santiago, Chile

${ }^{4}$ Department of Public Health and Community Medicine,

Section of Psychiatry, University of Verona, Italy

${ }^{5}$ Oslo University Hospital, Oslo, Norway

${ }^{6}$ Department of Medicine, Innlandet Hospital Trust,

Division Gjøvik, Oslo, Norway

${ }^{7}$ Institute of Health and Society, Faculty of Medicine, University of Oslo, Norway

${ }^{8}$ Division of General Paediatrics, University Hospitals of Geneva and Faculty of Medicine,

University of Geneva, Geneva, Switzerland

${ }^{9}$ Division of General Internal Medicine and Division of

Clinical Epidemiology, University Hospitals of Geneva, Switzerland

Correspondence to:

B Sadeghirad

sadeghb@mcmaster.ca

Additional material is published online only. To view please visit the journal online.

Cite this as: BMJ 2017;358:13887 http://dx.doi.org/10.1136/bmj.j3887

Accepted: 9 August 2017

\section{ABSTRACT}

OBJECTIVE

To estimate the benefits and harms of using corticosteroids as an adjunct treatment for sore throat.

\section{DESIGN}

Systematic review and meta-analysis of randomised control trials.

\section{DATA SOURCES}

Medline, Embase, Cochrane Central Register of Controlled Trials (CENTRAL), trial registries up to May 2017, reference lists of eligible trials, related reviews. STUDY SELECTION

Randomised controlled trials of the addition of corticosteroids to standard clinical care for patients aged 5 or older in emergency department and primary care settings with clinical signs of acute tonsillitis, pharyngitis, or the clinical syndrome of sore throat. Trials were included irrespective of language or publication status.

\section{REVIEW METHODS}

Reviewers identified studies, extracted data, and assessed the quality of the evidence, independently and in duplicate. A parallel guideline committee (BMJ Rapid Recommendation) provided input on the design and interpretation of the systematic review, including the selection of outcomes important to patients. Random effects model was used for metaanalyses. Quality of evidence was assessed with the GRADE approach.

\section{RESULTS}

10 eligible trials enrolled 1426 individuals. Patients who received single low dose corticosteroids (the most common intervention was oral dexamethasone with a maximum dose of $10 \mathrm{mg}$ ) were twice as likely to

\section{WHAT IS ALREADY KNOWN ON THIS TOPIC}

Short course corticosteroids are one adjunct treatment option for relief of symptoms in patients with sore throat

Corticosteroids are not commonly prescribed as clinicians are uncertain about the balance of benefits and harms and the applicability of the evidence to patients with less severe disease

\section{WHAT THIS STUDY ADDS}

Moderate to high quality evidence suggests the addition of one (or two) dose(s) of corticosteroids reduces the intensity and duration of pain in patients with sore throat with no increase in serious adverse effects

The mean time to complete pain resolution was about 11 hours shorter with corticosteroids, and about $18 \%$ more patients experienced complete pain relief at 48 hours

There were no subgroup effects between patients consulting at the emergency departments or primary care family practice

experience pain relief after 24 hours (relative risk 2.2, $95 \%$ confidence interval 1.2 to 4.3 ; risk difference $12.4 \%$; moderate quality evidence) and 1.5 times more likely to have no pain at 48 hours $(1.5,1.3$ to 1.8 ; risk difference $18.3 \%$; high quality). The mean time to onset of pain relief in patients treated with corticosteroids was 4.8 hours earlier ( $95 \%$ confidence interval -1.9 to -7.8 ; moderate quality) and the mean time to complete resolution of pain was 11.1 hours earlier ( -0.4 to -21.8 ; low quality) than in those treated with placebo. The absolute pain reduction at 24 hours (visual analogue scale 0-10) was greater in patients treated with corticosteroids (mean difference $1.3,95 \%$ confidence interval 0.7 to 1.9 ; moderate quality). Nine of the 10 trials sought information regarding adverse events. Six studies reported no adverse effects, and three studies reported few adverse events, which were mostly complications related to disease, with a similar incidence in both groups.

\section{CONCLUSION}

Single low dose corticosteroids can provide pain relief in patients with sore throat, with no increase in serious adverse effects. Included trials did not assess the potential risks of larger cumulative doses in patients with recurrent episodes of acute sore throat.

\section{SYSTEMATIC REVIEW REGISTRATION} PROSPERO CRD42017067808.

\section{Introduction}

Sore throat is among the most common presenting complaints in both emergency departments and outpatient care settings. It is the cause of about $5 \%$ of medical visits in children and about $2 \%$ of all outpatient visits in adults. ${ }^{1-3}$ The most common cause of sore throat is acute pharyngitis caused by self limiting viral infections. Pain management with paracetamol (acetaminophen) or non-steroidal antiinflammatory drugs (NSAIDs) therefore represents the mainstay of care. ${ }^{45}$ These drugs provide limited pain relief but also sometimes cause serious harm. ${ }^{67}$

Treatment of sore throat with antibiotics also provides modest benefit in reduction of symptoms and fever when the infection is bacterial, but their use could contribute to antibiotic resistance. ${ }^{89}$ Although most cases of sore throat have a viral aetiology, and the risk of secondary complications is low, clinicians commonly prescribe antibiotics. ${ }^{410}$ Though this could be because clinicians think that patients seeking care expect a course of antibiotics, in reality pain relief might be more important to them. ${ }^{10}$

Corticosteroids represent an additional therapeutic option for symptom relief. Randomised control trials 
suggest that a short course of low-to-moderate dose corticosteroids probably provides symptomatic benefit to patients with sore throat. ${ }^{11-14}$ Despite this evidence, clinicians do not commonly use steroids. Reasons might include uncertain applicability of the evidence to patients with less severe disease, as the initial studies enrolled only patients with severe sore throat presenting to emergency departments, almost all of whom received antibiotics.

This systematic review is part of the $B M J$ Rapid Recommendations project, a collaborative effort from the MAGIC research and innovation programme (www. magicproject.org) and $B M J$. The aim of the project is to respond to new potentially practice changing evidence and provide a trustworthy practice guideline in a timely manner. ${ }^{15}$ In this case, the stimulus was the recent TOAST (Treatment Options without Antibiotics for Sore Throat) trial, which randomised over 500 patients with sore throat presenting to their primary care clinician who were not initially prescribed antibiotics; the TOAST authors reported beneficial effects of corticosteroids. ${ }^{16}$ In the light of this new potentially practice changing evidence, we updated the latest Cochrane review ${ }^{12}$ dealing with the effectiveness and safety of corticosteroids as an adjunct treatment for sore throat in addition to standard care compared with standard care alone. This systematic review informed the parallel guideline published in a multilayered electronic format on bmj.com ${ }^{17}$ and MAGICapp (https://www.magicapp.org/goto/guideline/JjXYAL/ section/j79pvn).

\section{Methods}

Guideline panel and patient involvement

According to the BMJ Rapid Recommendations process, ${ }^{15}$ a guideline panel provided critical oversight to the review and identified populations, subgroups, and outcomes of interest. The panel included clinicians, methodologists, and patients with experience of sore throat. Patients received personal training and support to optimise contributions throughout the guideline development process. The patients on the panel led the interpretation of the results based on what they expected the typical patient values and preferences to be, as well as the variation between patients. Five patient representatives were full members of the guideline panel and contributed to the selection and prioritisation of outcomes, values and preferences assessments, and critical feedback to the protocol for the systematic review and the BMJ Rapid Recommendations manuscript.

\section{Search strategy}

We searched Medline, Embase, and the Cochrane Central Register of Controlled Trials (CENTRAL) for relevant published randomised controlled trials based on the strategy reported in the most recent Cochrane systematic review, ${ }^{12}$ modified under the guidance of a research librarian (appendix 1). We limited the search from 1 January 2010, which included a two month overlap with the previous Cochrane review search, ${ }^{12}$ to 1 May 2017. There were no language restrictions. We reviewed reference lists from eligible new trials and related reviews for additional eligible trials and searched ClinicalTrials.gov for ongoing or unpublished trials and for additional data from published trials.

\section{Study selection}

Reviewers (BS, RACS, DP, RBP) independently and in duplicate screened the titles and abstracts of all identified studies using a priori selection criteria. Subsequently, the samereviewersindependently assessed eligibility of the full texts of potentially eligible studies. Reviewers resolved discrepancies through discussion or, if needed, by adjudication from a third reviewer.

We included randomised controlled trials that compared corticosteroids with standard of care or placebo and enrolled adults and/or children aged 5 and over in emergency departments and primary care settings with a clinical syndrome of sore throat (painful throat, odynophagia, or pharyngitis).

We excluded studies of participants who were admitted to hospital or immunocompromised and those with infectious mononucleosis, sore throat after any surgery or intubation (postoperative sore throat), gastroesophageal reflux disease, croup, or peritonsillar abscess. We also excluded studies that enrolled children aged under 5 because they would not be able to provide trustworthy outcome measurements, especially for self reported pain.

Our outcomes of interest were complete resolution of pain at 24 and 48 hours; mean time to onset of pain relief; mean time to complete resolution of pain; absolute reduction of pain at 24 hours; duration of $\mathrm{bad} /$ non-tolerable symptoms (such as problems for eating, drinking, swallowing); recurrence/relapse of symptoms; days missed from school or work; need for antibiotics; and rate of adverse events related to treatment. We included any adverse events reported by the authors.

\section{Data abstraction and risk of bias assessment}

Reviewers extracted the following data, independently and in duplicate: general study information (authors, publication year, and study location); study population details (sample size, age, diagnosis, and percentage of participants with confirmed group $A \beta$ haemolytic streptococcus (GAS) pharyngitis or culture positive for bacterial pathogens); setting (primary care versus hospital emergency department); details on the intervention and comparison (for example, type, form, duration, and dose of corticosteroids; type of control group); co-interventions (proportion of participants who received antibiotics and/or analgesics); and outcomes as listed above.

In randomised controlled trials with more than two arms, we extracted data from the arm closest to a single dose regimen or data from the arm that received corticosteroid as adjunct treatment to standard of care rather than instead of standard of care. In trials with data for both oral and parenteral corticosteroids, we 
used oral data for the main analysis and intramuscular data for the appropriate subgroup analysis.

Two reviewers independently assessed risk of bias using the modified Cochrane risk of bias instrument, ${ }^{1819}$ which deals with random sequence generation; allocation concealment; blinding of study participants, healthcare providers, and outcome assessors; incomplete outcome data; and other potential sources of bias. Reviewers classified studies at high risk of bias when they had rated at least one item as high risk of bias.

To assess the quality of evidence, we used the GRADE (Grading of Recommendations, Assessment, Development, and Evaluation) approach that classifies evidence as high, moderate, low, or very low quality based on considerations of risk of bias, consistency, directness, precision, and publication bias. ${ }^{20} \mathrm{We}$ resolved disagreements between reviewers in data extraction and assessments of risk of bias or quality of evidence by discussion and, if needed, by third party adjudication. We used the MAGICapp platform to generate the GRADE summary of findings table.

\section{Data synthesis and statistical methods}

For continuous outcomes, we calculated the mean difference and its corresponding 95\% confidence interval. For dichotomous outcomes, we calculated the relative risk and its corresponding 95\% confidence interval and determined the absolute effect by multiplying the relative risk and its confidence interval with the estimated baseline risk. The median of the placebo group of included randomised controlled trials provided the baseline risk.

Statistical heterogeneity was determined with the Q statistic and $\mathrm{I}^{2}$. We used the DerSimonian-Laird random effects model for the meta-analysis of all outcomes. Regardless of the observed statistical heterogeneity, we conducted the following prespecified subgroup analyses when each subgroup was represented by at least two studies: age (children $v$ adults), postulating a larger effect in adults; route of administration of corticosteroids (oral $v$ parenteral), postulating a larger effect for parenteral; presence or absence of positive results on culture for a bacterial pathogen or direct antigen test for group A $\beta$ haemolytic streptococcus, postulating a larger effect in patients with positive test results; initial setting (emergency departments $V$ family practice), postulating a larger effect in patients consulting the emergency department; and place of subsequent care (admitted to hospital $v$ outpatient), postulating a larger effect among the patients admitted. For subgroup analysis, we tested for interaction using a $\chi^{2}$ significance test. ${ }^{21}$ We planned to examine publication bias using funnel plots for outcomes for which data from 10 or more studies were available. ${ }^{22}$ Data were analysed with STATA software (version 14.2, TX, USA).

\section{Patient involvement}

Five patient representatives were full members of the guideline panel, and contributed to the selection and prioritisation of outcomes, values and preferences assessments, and critical feedback to the protocol for the systematic review and the BMJ Rapid Recommendations manuscript.

\section{Results}

\section{Description of included studies}

We identified 2349 titles and abstracts through our literature search, of which 46 were potentially eligible and 36 were excluded (19 were not randomised trials; 14 had no patients with sore throat/acute pharyngitis; in three corticosteroids were not among the interventions or were not compared with a placebo/ usual care). Figure 1 shows the details of study selection process.

The 10 randomised controlled trials that proved eligible enrolled 1426 individuals. Eight studies recruited patients from hospital emergency departments ${ }^{23-30}$ and two from primary care. ${ }^{1631}$ Three studies enrolled children, ${ }^{27-29}$ six studies enrolled adults, ${ }^{16}$ 24-26 3031 and one study included both children and adults. ${ }^{23}$ Oral dexamethasone (single dose of $10 \mathrm{mg}$ for adults and $0.6 \mathrm{mg} / \mathrm{kg}$, maximum 10 mg for children) was the most common intervention (five studies) followed by single dose intramuscular injection of dexamethasone (three studies). All patients in three trials received both antibiotics and analgesics as the usual care ${ }^{252630}$; in two trials, all patients received antibiotics, while analgesics were prescribed at the physician's discretion. ${ }^{23}{ }^{24}$ In the five remaining trials, patients in usual care group received antibiotics or analgesics at the physician's discretion. ${ }^{16}$ 27-29 31 Table 1 presents study details.

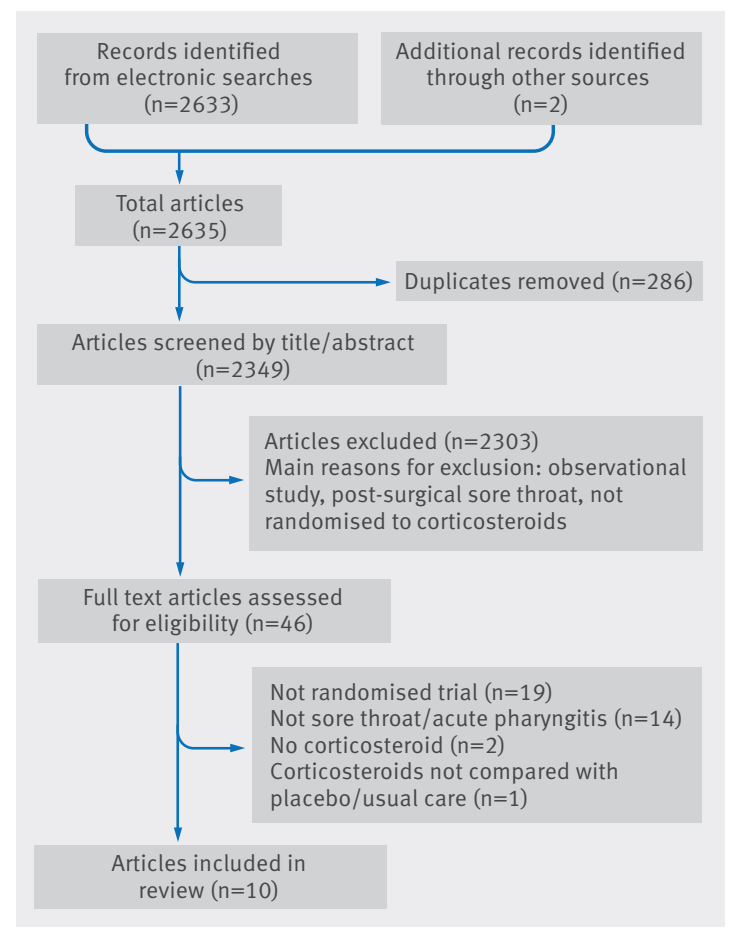

Fig 1 | Selection of studies in review of corticosteroids for treatment of sore throat 


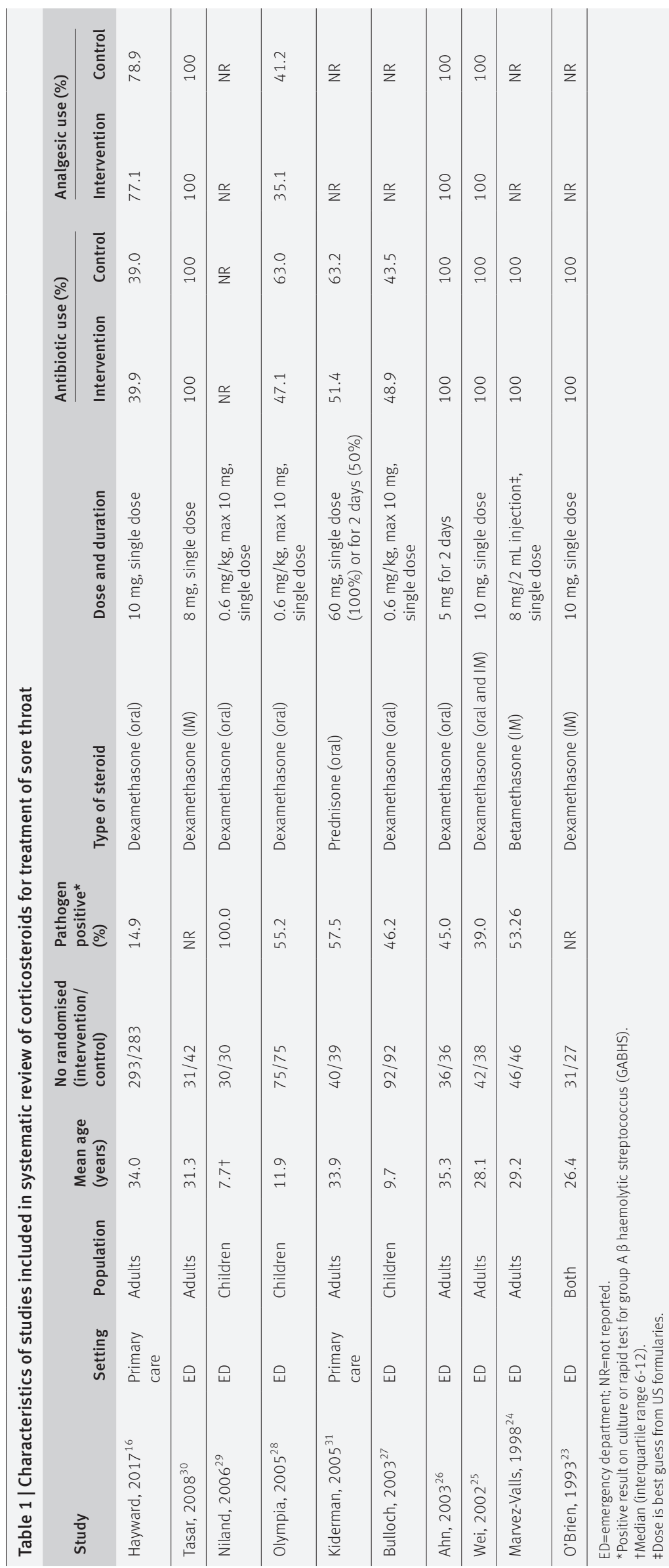

Among the included studies, four randomised controlled trials were at high risk of bias. ${ }^{23} 242628$ One study had issues in more than one category of risk. ${ }^{26}$ The three remaining studies had issues in concealment of the treatment allocation, incomplete outcome reporting, and blinding of outcome assessors. Appendix 2 summarises the risk of bias assessments.

Table 2 shows findings for all outcomes. Interactive tables summarising findings are available at https:// www.magicapp.org/goto/guideline/JjXYAL/section/ j79pvn

\section{Pain}

In the five randomised controlled trials that reported complete resolution of symptoms at 24 hours, ${ }^{16} 25$ 29-31 patients who received a single dose of corticosteroids were twice as likely to experience complete symptom resolution than placebo patients (relative risk 2.24, $95 \%$ confidence interval 1.17 to $4.29 ; \mathrm{I}^{2}=69 \%, 22.4 \%$ V 10.0\%; moderate quality evidence; fig 2, table 2). All studies reporting this outcome were at low risk of bias. Tests of interaction showed no evidence of any subgroup effect (table A in appendix 3).

In the four trials that reported complete resolution of pain at 48 hours, ${ }^{16}$ 29-31 patients treated with corticosteroids were $50 \%$ more likely to experience complete resolution (relative risk 1.48, 95\% confidence interval 1.26 to $1.75 ; \mathrm{I}^{2}=3 \%, 60.8 \% \mathrm{~V}$ $42.5 \%$; high quality; fig 3 , table 2 ). These four studies were all at low risk of bias, and tests of interaction showed no evidence of any subgroup effect (table A in appendix 3).

In the eight studies that reported mean time to onset of pain relief, ${ }^{16}{ }^{23-28} 30$ patients who received corticosteroids experienced onset of pain relief on average 4.8 hours earlier than those who received placebo (95\% confidence interval -1.9 to -7.8 ; $\mathrm{I}^{2}=78 \%$; moderate quality; fig 4 , table 2 ). We found no evidence of subgroup effect for this outcome (table A in appendix 3).

Time to complete resolution of pain was reported in six studies. ${ }^{162324272830}$ On average, patients receiving a single dose corticosteroid experienced complete resolution 11.1 hours earlier (95\% confidence interval -0.4 to -21.8 ; $I^{2}=85 \%$; low quality; fig 5 , table 2 ). In our subgroup analysis, we found a significantly larger effect among those treated with intramuscular corticosteroids (mean difference -22.4 (95\% confidence interval -27.3 to -17.5$)$ and $-1.5(-12.6$ to 9.5), for intramuscular and oral corticosteroids, respectively; $\mathrm{P}=0.001$ for interaction); however, the effect modification is suggested by comparison between rather than within studies. We found no other subgroup effect (table B in appendix 3).

Meta-analysis from eight studies that assessed pain with a visual analogue scale $(0=$ no pain, $10=$ maximum pain) at baseline and after 24 hours $^{1623-2831}$ showed a 1.3 points lower pain score among patients treated with corticosteroids compared with those treated with placebo at 24 hours (95\% confidence interval 0.7 to 1.9 ; $\mathrm{I}^{2}=65 \%$; moderate quality; fig 6 , table 2 ). We 


\begin{tabular}{|c|c|c|c|c|c|c|}
\hline \multirow{2}{*}{$\begin{array}{l}\text { Outcome and } \\
\text { timeframe }\end{array}$} & \multirow{2}{*}{$\begin{array}{l}\text { Study results }(95 \% \mathrm{Cl}) \\
\text { and measurements }\end{array}$} & \multicolumn{3}{|c|}{ Absolute effect estimates } & \multirow{2}{*}{$\begin{array}{l}\text { Quality of } \\
\text { evidence }\end{array}$} & \multirow[b]{2}{*}{ Summary } \\
\hline & & No corticosteroids & Corticosteroids & Difference $(95 \% \mathrm{Cl})$ & & \\
\hline $\begin{array}{l}\text { Complete resolution } \\
\text { of pain at } 24 \text { hours }\end{array}$ & $\begin{array}{l}\text { Relative risk: } 2.24 \text { ( } 1.17 \\
\text { to } 4.29) .1049 \text { patients } \\
\text { in } 5 \text { studies }\end{array}$ & $100 / 1000$ & $224 / 1000$ & $\begin{array}{l}124 \text { more }(17 \text { more } \\
\text { to } 329 \text { more }\end{array}$ & $\begin{array}{l}\text { Moderate (in- } \\
\text { consistency and } \\
\text { imprecision)* } † \ddagger\end{array}$ & $\begin{array}{l}\text { Corticosteroids probably } \\
\text { increase chance of com- } \\
\text { plete resolution of pain at } \\
24 \text { hours }\end{array}$ \\
\hline $\begin{array}{l}\text { Complete resolution } \\
\text { of pain at } 48 \text { hours }\end{array}$ & $\begin{array}{l}\text { Relative risk: } 1.48 \text { ( } 1.26 \\
\text { to } 1.75) .1076 \text { patients } \\
\text { in } 4 \text { studies }\end{array}$ & $425 / 1000$ & $629 / 1000$ & $\begin{array}{l}204 \text { more (111 } \\
\text { more to } 319 \text { more) }\end{array}$ & High $\neq$ & $\begin{array}{l}\text { Corticosteroids increase } \\
\text { chance of complete resolu- } \\
\text { tion of pain at } 48 \text { hours }\end{array}$ \\
\hline $\begin{array}{l}\text { Recurrence/relapse } \\
\text { of symptoms }\end{array}$ & $\begin{array}{l}\text { Relative risk: } 0.52 \text { ( } 0.16 \\
\text { to } 1.73) .372 \text { patients in } \\
3 \text { studies }\end{array}$ & $65 / 1000$ & $34 / 1000$ & $\begin{array}{l}31 \text { fewer ( } 55 \text { fewer } \\
\text { to } 47 \text { more) }\end{array}$ & $\begin{array}{l}\text { Moderate (serious } \\
\text { imprecision) } § \text { ๆ }\end{array}$ & $\begin{array}{l}\text { Corticosteroids probably } \\
\text { have no important effect on } \\
\text { chance that symptoms recur }\end{array}$ \\
\hline $\begin{array}{l}\text { Antibiotics } \\
\text { prescription }\end{array}$ & $\begin{array}{l}\text { Relative risk: } 0.83 \text { ( } 0.61 \\
\text { to } 1.13) .342 \text { patients } \\
\text { in } 1 \text { study. Follow-up } 28 \\
\text { days }\end{array}$ & $564 / 1000$ & $468 / 1000$ & $\begin{array}{l}96 \text { fewer ( } 220 \text { fewer } \\
\text { to } 73 \text { more) }\end{array}$ & $\begin{array}{l}\text { Low (very serious } \\
\text { imprecision)** }\end{array}$ & $\begin{array}{l}\text { Corticosteroids might } \\
\text { decrease chance of taking } \\
\text { antibiotics in patients given } \\
\text { prescription with instruc- } \\
\text { tions to take antibiotic if } \\
\text { unimproved or worse }\end{array}$ \\
\hline $\begin{array}{l}\text { Mean time to onset } \\
\text { of pain relief (hours) }\end{array}$ & 907 patients in 8 studies & 12.3 hours & 7.4 hours & $\begin{array}{l}4.8 \text { fewer ( } 7.8 \text { fewer } \\
\text { to } 1.9 \text { fewer) }\end{array}$ & 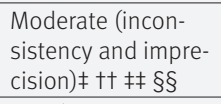 & $\begin{array}{l}\text { Corticosteroids probably } \\
\text { shorten the time until pain } \\
\text { starts to improve. }\end{array}$ \\
\hline $\begin{array}{l}\text { Mean time to } \\
\text { complete resolution } \\
\text { of pain (hours) }\end{array}$ & 720 patients in 6 studies & 44.0 hours & 33.0 hours & $\begin{array}{l}11.1 \text { fewer ( } 21.8 \\
\text { fewer to } 0.4 \text { fewer) }\end{array}$ & 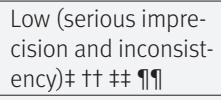 & $\begin{array}{l}\text { Corticosteroids might short- } \\
\text { en duration of pain }\end{array}$ \\
\hline $\begin{array}{l}\text { Pain reduction } \\
24 \text { hours }\end{array}$ & $\begin{array}{l}\text { Scale: high better. } 1247 \\
\text { patients in } 8 \text { studies }\end{array}$ & Mean 3.3 hours & Mean 4.6 hours & $\begin{array}{l}1.3 \text { higher ( } 0.7 \text { high- } \\
\text { er to } 1.9 \text { higher) }\end{array}$ & $\begin{array}{l}\text { Moderate (incon- } \\
\text { sistency and impre- } \\
\text { cision) } \ddagger \dagger † \ddagger \ddagger \star \star \star\end{array}$ & $\begin{array}{l}\text { Corticosteroids probably } \\
\text { reduce severity of pain at } \\
24 \text { hours }\end{array}$ \\
\hline $\begin{array}{l}\text { Duration of bad/ } \\
\text { non-tolerable } \\
\text { symptoms }\end{array}$ & - & - & - & 0 (0 to 0$)$ & - & $\begin{array}{l}\text { No studies provided infor- } \\
\text { mation on this outcome }\end{array}$ \\
\hline $\begin{array}{l}\text { Days missed from } \\
\text { work or school }\end{array}$ & $\begin{array}{l}181 \text { patients in } 2 \text { studies. } \\
\text { Follow-up to } 14 \text { days }\end{array}$ & \multicolumn{3}{|c|}{$\begin{array}{l}\text { Two trials reported days missed from work/school. In Kiderman et } \\
\text { al, } 22 / 40 \text { ( } 55 \% \text { ) in steroids group and } 27 / 39(69 \%) \text { in placebo } \\
\text { group took time off work (relative risk } 0.79,95 \% \mathrm{Cl} 0.56 \text { to } 1.13) \text {. } \\
\text { Marvez-Valls et al reported average time patients in each arm } \\
\text { missed from work/school: average } 0.4 \text { (SD } 1.4) \text { days in interven- } \\
\text { tion group adults } v \text { and } 0.7 \text { (SD } 1.4) \text { days in placebo group adults; } \\
\text { mean difference } 0.30 \text { days, }-0.28 \text { to } 0.88 \text { ) }\end{array}$} & $\begin{array}{l}\text { Moderate (serious } \\
\text { imprecision and } \\
\text { some concerns of } \\
\text { risk of bias)††† fł‡ }\end{array}$ & $\begin{array}{l}\text { Corticosteroids probably } \\
\text { have no important effect } \\
\text { on days missed from work } \\
\text { or school }\end{array}$ \\
\hline $\begin{array}{l}\text { Serious adverse } \\
\text { events }\end{array}$ & $\begin{array}{l}808 \text { patients in } 3 \text { studies. } \\
\text { Follow-up to } 10 \text { days }\end{array}$ & \multicolumn{3}{|c|}{$\begin{array}{l}\text { Few adverse effects reported in trials, mostly disease related } \\
\text { complications, and occurred with similar frequency in intervention } \\
\text { and control groups (see table } 3 \text { ) }\end{array}$} & Moderate§§§ & $\begin{array}{l}\text { Corticosteroids probably do } \\
\text { not increase risk of adverse } \\
\text { events }\end{array}$ \\
\hline
\end{tabular}

${ }^{*}$ Considerable heterogeneity $\left(1^{2}=69 \%\right)$. Not rated down because clinical inconsistency was deemed not important as all results of included studies have similar clinical implication.

tLimits of confidence interval suggest small benefit in one extreme and benefit important to patients in other. Because imprecision is linked to inconsistency, certainty of evidence rated down by

only one level.

‡Publication bias not tested because of small number of studies.

$\S$ Not rated down for risk of bias as one of three trials judged to be at high risk of bias from missing participant data.

१Confidence interval suggests that corticosteroids increase chance of recurrence of symptoms in one extreme but decrease this chance in other extreme.

${ }^{* *}$ Confidence interval suggest that corticosteroids could largely reduce chance of taking antibiotics in one extreme but could slightly increase this chance in other extreme.

††Not rated down for risk of bias as equal number of trials judged to be at high and low risk of bias, but P value for test of interaction showed no difference between two estimates.

¥łLarge unexplained clinical and statistical inconsistency.

$\S \S C$ Confidence interval suggests small benefit in one extreme and benefit that some patients might consider important in other extreme. As this imprecision was result of inconsistency, certainty of

evidence rated down by only one level.

११ Confidence interval suggests trivial benefit in one extreme and benefit that would be considered important by most patients in other extreme.

${ }^{* * *}$ Confidence interval suggests small benefit in one extreme and benefit important to patients in other. As this imprecision was related to inconsistency, rated down by only one level.

t†tOne study was at high risk of bias from concerns with regards to allocate concealment.

$¥ \neq \ddagger$ Studies showed that corticosteroids could increase days missed from school or work in one extreme but decrease them in other extreme.

$\S \S \S$ High risk of bias studies showed similar results as low risk of bias studies; however, high risk of selective outcome reporting was possible.

found no evidence of subgroup effect for this outcome (table B in appendix 3).

To assess the possibility that there was selective reporting, we examined the magnitude of effect on the time to onset of pain relief, time to complete resolution of pain, and absolute pain reduction in studies that did and did not report resolution of pain at 24 and 48 hours. The magnitude of effect on the other pain outcomes was similar in both sets of studies, making selective reporting less likely (table $\mathrm{C}$ in appendix 3 ).

\section{Other outcomes}

The authors of one study reported a possible decrease in the likelihood of receipt of antibiotics in patients treated with corticosteroids (relative risk 0.83, 95\% confidence interval 0.61 to 1.13 ; moderate quality). ${ }^{16}$ Three studies $^{27} 2831$ suggested a possible lower risk of recurrence/relapse of the symptoms $(0.52,0.16$ to $1.73 ; \mathrm{I}^{2}=23 \%$; moderate quality, table D in appendix 3 , table 2).

Kiderman and colleagues reported that 22/40 (55\%) patients treated with corticosteroids and 27/39 (69\%) taking placebo took time off work because of sore throat (relative risk 0.8, 95\% confidence interval 0.6 to 1.1). ${ }^{31}$ Marvez-Valls and colleagues reported that adult patients treated with corticosteroids missed an average of 0.4 (SD 1.4) days, whereas patients in the placebo arm missed an average of 0.7 (SD 1.4) days (mean 


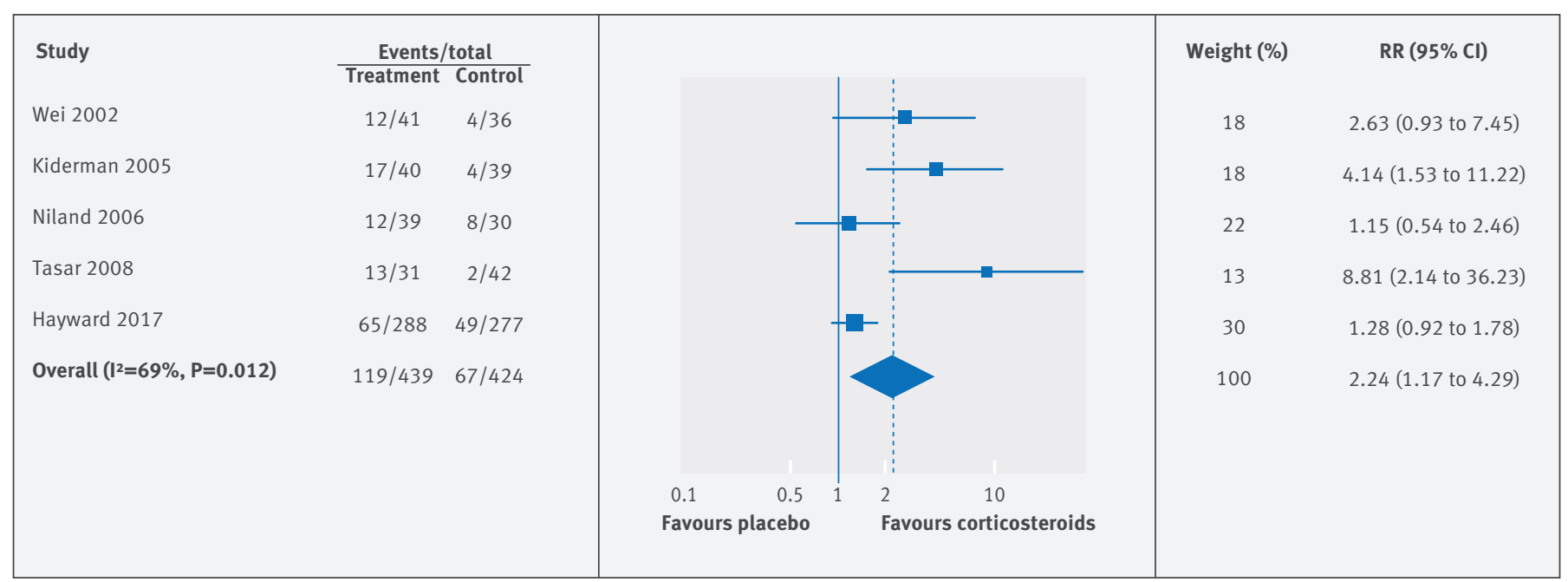

Fig 2 | Relative risk for complete resolution of pain at 24 hours for corticosteroid $v$ placebo groups in review of treatment of sore throat. Pooled relative risk calculated by DerSimonian-Laird random effects model

difference -0.3 days, 95\% confidence interval -0.87 to 0.27$).{ }^{24}$ None of the trials reported duration of bad/ non-tolerable symptoms.

All studies except one sought information on adverse effects using different methods including standardised questionnaire (two studies), open ended questions or diaries to capture self reported adverse events (five studies), or a checklist of complications (two studies). Table 3 provides details of adverse effects assessed and methods used for capturing them. Six studies reported no adverse effects, and three studies reported adverse events, in both steroids and comparator arms, which were mostly complications related to disease and occurred with similar frequency in the intervention and control groups (table 3). Hayward and colleagues reported two serious adverse events (admission to hospital for pharyngeal or peritonsillar abscess, tonsillitis, and pneumonia) in the corticosteroids group $(0.7 \%)$ and three in the placebo group $(1.1 \%) .{ }^{16}$
Olympia and colleagues reported one out of the 57 $(1.8 \%)$ children in the corticosteroids group and two out of the $68(2.9 \%)$ children in the placebo group developed a peritonsillar abscess (moderate quality, table 2 and table 3$).^{28}$

\section{Discussion}

In patients with acute sore throat, there is primarily moderate to high quality evidence that one or two low doses of corticosteroids reduces the intensity and duration of pain-pain scores at 24 hours, complete resolution of pain at 24 and at 48 hours, time to onset of pain relief, and time to complete pain relief. In this review, results were consistent across studies and across all pain outcomes (table 2). The reduction in pain achieved was modest-for example, mean time to complete resolution of pain was about 11 hours shorter, and about $18 \%$ more patients had complete pain relief at 48 hours. At 24 hours, the mean improvement in

\begin{tabular}{|c|c|c|c|c|c|c|}
\hline Study & $\begin{array}{c}\text { Events/ } \\
\text { Treatment }\end{array}$ & $\frac{s / \text { total }}{\mathrm{t} \text { Control }}$ & & & Weight (\%) & $\operatorname{RR}(95 \% \mathrm{Cl})$ \\
\hline Kiderman 2005 & $23 / 40$ & $13 / 39$ & & 1 & 10 & $1.73(1.03$ to 2.89$)$ \\
\hline Tasar 2008 & $29 / 31$ & $22 / 472$ & & $\rightarrow$ & 29 & 1.79 (1.32 to 2.42$)$ \\
\hline Hayward 2017 & $102 / 288$ & $75 / 277$ & & $\rightarrow$ & 42 & 1.31 (1.02 to 1.68$)$ \\
\hline \multirow{2}{*}{ Overall $\left(I^{2}=3 \%, P=0.377\right)$} & & & 0.5 & 10 & & \\
\hline & & & Favours placebo & Favours corticosteroids & & \\
\hline
\end{tabular}

Fig 3 | Relative risk for complete resolution of pain at 48 hours for corticosteroid $v$ placebo groups in review of treatment of sore throat. Pooled relative risk calculated by DerSimonian-Laird random effects model 


\begin{tabular}{|c|c|c|c|c|c|c|c|c|}
\hline \multirow[t]{2}{*}{ Study } & \multicolumn{2}{|c|}{ Treatment } & \multicolumn{2}{|c|}{ Control } & & & \multirow{2}{*}{$\begin{array}{l}\text { Weight } \\
\text { (\%) }\end{array}$} & \multirow{2}{*}{$\begin{array}{c}\text { Weighted Mean } \\
\text { Difference }(95 \% \mathrm{CI})\end{array}$} \\
\hline & No in group & Mean (SD) time & No in group & Mean (SD) time & & & & \\
\hline O’Brien 1994 & 26 & $6.3(5.3)$ & 25 & $12.4(8.5)$ & & & 13 & $-6.10(-10.1$ to -2.19$)$ \\
\hline Marvez-Valls 1998 & 46 & $6.3(8.1)$ & 46 & $11.3(8.1)$ & & & 13 & $-5.00(-8.31$ to -1.69$)$ \\
\hline Wei 2002 & 42 & $7.4(5.32)$ & 35 & $12.1(8.7)$ & & & 13 & $-4.66(-7.97$ to -1.36$)$ \\
\hline Bulloch 2003 & 92 & $9.58(18.4)$ & 92 & $10.1(15.2)$ & & & 11 & $-0.51(-5.39$ to 4.37$)$ \\
\hline Ahn 2003 & 36 & $5.11(6.4)$ & 38 & $6.48(8.3)$ & & & 13 & $-1.37(-4.74$ to 2.00$)$ \\
\hline Olympia 2005 & 57 & $9.2(7.5)$ & 68 & $18.2(18.3)$ & & & 11 & $-9.00(-13.77$ to -4.23$)$ \\
\hline Tasar 2008 & 31 & $8.1(4.9)$ & 42 & $19.9(9.4)$ & & & 13 & $-11.80(-15.13$ to -8.47$)$ \\
\hline Hayward 2017 & 129 & $27.5(17.4)$ & 102 & $27.0(18.1)$ & & & 12 & $0.50(-4.12$ to 5.12$)$ \\
\hline \multirow[t]{2}{*}{ Overall $\left(\left.\right|^{2}=78 \%, P=0.000\right)$} & 459 & & 448 & & & & 100 & $-4.84(-7.75$ to -1.93 \\
\hline & & & & & $\begin{array}{lll}-15 & -10 & -5\end{array}$ & $\begin{array}{cc}5 & 10 \\
\text { Favours placebo }\end{array}$ & & \\
\hline
\end{tabular}

Fig 4 | Weighted mean difference in mean time to onset of pain relief (hours) between corticosteroids and placebo groups in review of treatment of sore throat. Pooled mean difference was calculated by DerSimonian-Laird random effects model

pain scores was about $13 \mathrm{~mm}$ on a visual analogue scale from 0 to $100 \mathrm{~mm}$ (with the minimal important difference being about $10 \mathrm{~mm}) .^{32}$ The relative effects were similar across severities, though patients with less severe sore throat had less absolute benefit from corticosteroids. The balance of benefits and harms therefore almost certainly depends on the severity of the patient's sore throat.

Whether corticosteroids reduce recurrence/relapse of symptoms, number of days missed from school or work, duration of bad/intolerable symptoms, or antibiotic use remains uncertain. Regarding the safety of the short courses and low doses of corticosteroids, studies reported few adverse effects, with no apparent increase in events in patients treated with corticosteroid.

\section{Strengths and limitations of study}

Strengths of this review include explicit eligibility criteria; a comprehensive search developed with a research librarian; duplicate assessment of eligibility, risk of bias, and data abstraction; consideration of all outcomes important to patients; consideration of selective reporting bias; consideration of possible subgroup effects; and rigorous use of the GRADE approach to rate quality of evidence. The limitations of our review have to do with the underlying evidence. Only three trials explicitly reported adverse events, and they did so inconsistently. ${ }^{162528}$ We observed substantial statistical heterogeneity in some of the outcomes. We explored the source(s) of heterogeneity by subgroup analysis and rated down for inconsistency in GRADE assessments for outcomes with unexplained heterogeneity.

\begin{tabular}{|c|c|c|c|c|c|c|c|c|}
\hline \multirow[t]{2}{*}{ Study } & \multicolumn{2}{|c|}{ Treatment } & \multicolumn{2}{|c|}{ Control } & & & \multirow{2}{*}{$\begin{array}{l}\text { Weight } \\
\text { (\%) }\end{array}$} & \multirow{2}{*}{$\begin{array}{c}\text { Weighted Mean } \\
\text { Difference }(95 \% \mathrm{Cl})\end{array}$} \\
\hline & No in group & Mean (SD) time & No in group & Mean (SD) time & & & & \\
\hline O’Brien 1994 & 26 & $15.0(11.4)$ & 25 & $35.4(17.9)$ & $\longrightarrow$ & & 18 & $-20.40(-28.67$ to -12.13$)$ \\
\hline Marvez-Valls 1998 & 46 & $42.0(43.3)$ & 46 & $55.8(43.9)$ & & - & 13 & $-13.80(-31.62$ to 4.02$)$ \\
\hline Bulloch 2003 & 92 & $45.1(36.9)$ & 92 & $42.8(35.4)$ & & + & 17 & $2.33(-8.12$ to 12.78$)$ \\
\hline Olympia 2005 & 57 & $30.3(27.8)$ & 68 & $43.8(43.5)$ & & & 16 & $-13.50(-26.11$ to -0.89$)$ \\
\hline Tasar 2008 & 31 & $28.9(12.0)$ & 42 & $53.7(16.2)$ & $\longrightarrow$ & & 19 & $-24.80(-31.27$ to -18.33$)$ \\
\hline Hayward 2017 & 101 & $65.8(48.1)$ & 94 & $60.0(38.9)$ & & $\rightarrow$ & 16 & $5.80(-6.45$ to 18.05$)$ \\
\hline Overall $\left(I^{2}=85 \%, P=0.000\right)$ & 353 & & 367 & & & & 100 & $-11.11(-21.83$ to -0.40$)$ \\
\hline & & & & & $\begin{array}{ccc}-15 \quad-10 & -5 \\
\text { Favours } & -5 \\
\text { corticosteroids }\end{array}$ & $\begin{array}{l}5 \quad 10 \\
\text { Favours } \\
\text { placebo }\end{array}$ & & \\
\hline
\end{tabular}

Fig 5 | Weighted mean difference in mean time to complete resolution of pain (hours) between corticosteroids and placebo groups in review of treatment of sore throat. Pooled mean difference calculated by DerSimonian-Laird random effects model 


\begin{tabular}{|c|c|c|c|c|c|c|c|}
\hline \multirow[t]{2}{*}{ Study } & \multicolumn{2}{|c|}{ Treatment } & \multicolumn{2}{|c|}{ Control } & & \multirow{2}{*}{$\begin{array}{c}\text { Weight } \\
\text { (\%) }\end{array}$} & \multirow{2}{*}{$\begin{array}{l}\text { Weighted Mean } \\
\text { Difference }(95 \% \mathrm{Cl})\end{array}$} \\
\hline & No in group & Mean (SD) time & No in group & Mean (SD) time & & & \\
\hline O’Brien 1994 & 26 & $5.67(2.4)$ & 25 & $4.33(2.6)$ & & 10 & $1.33(-0.04$ to 2.71$)$ \\
\hline Marvez-Valls 1998 & 46 & $5.5(2.7)$ & 46 & $3.9(2.7)$ & & 12 & 1.60 (0.50 to 2.70$)$ \\
\hline Wei 2002 & 41 & $4.6(1.9)$ & 36 & $3.6(2.6)$ & & 13 & 1.00 (-0.03 to 2.03$)$ \\
\hline Bulloch 2003 & 92 & $2.65(2.79)$ & 92 & $2.46(2.29)$ & $\rightarrow$ & 15 & 0.19 (-0.55 to 0.92$)$ \\
\hline Ahn 2003 & 36 & $4.97(2.2)$ & 38 & $3.06(2.2)$ & & 13 & 1.91 (0.91 to 2.91$)$ \\
\hline Kiderman 2005 & 40 & $5.6(2.27)$ & 39 & $2.9(2.54)$ & $\longrightarrow$ & 12 & 2.70 (1.64 to 3.76$)$ \\
\hline Olympia 2005 & 57 & $5.8(2.6)$ & 68 & $4.3(3.0)$ & $⺊$ & 13 & 1.50 (0.52 to 2.48$)$ \\
\hline Hayward 2017 & 288 & $1.92(1.94)$ & 277 & $1.59(9.67)$ & $\Rightarrow$ & 12 & $0.33(-0.83$ to 1.49$)$ \\
\hline Overall $\left(I^{2}=65 \%, P=0.005\right)$ & 626 & & 621 & & & 100 & 1.30 (0.68 to 1.92$)$ \\
\hline & & & & & $\begin{array}{ccccccccc}-3 & -2 & -1 & 0 & 1 & 2 & 3 & 4 & 5 \\
\text { Favours placebo } & \text { Favours corticosteroids }\end{array}$ & & \\
\hline
\end{tabular}

Fig 6 Weighted mean difference in absolute reduction of pain at 24 hours $(0-10 ; 0=$ no pain, $10=$ maximum pain) between corticosteroids and placebo groups in review of treatment of sore throat. Pooled mean difference calculated by DerSimonian-Laird random effects model

In comparison with previous systematic reviews, ${ }^{11} 12$ we included two additional randomised controlled trials, ${ }^{16}{ }^{26}$ which almost doubled the number of participants. Results from our meta-analysis are consistent with previous findings that corticosteroids reduce pain at 48 hours and probably reduce other pain outcomes. In addition to enhanced precision with the additional studies, our meta-analysis adds to the existing evidence in that we considered absolute in addition to relative effect measures, providing a clear picture of the magnitude of effect. ${ }^{33}$ In part because of input from the guideline panel, we considered additional outcomes that participating patients considered important, including risk of recurrence of symptoms, duration of bad/non-tolerable symptoms, need for antibiotics, and days missed from school or

\begin{tabular}{|c|c|c|c|}
\hline Study & Methods used to assess adverse effects & Adverse effects assessed* & Adverse effects reported \\
\hline O’Brien, 1993 & Standardised questionnaire & Nausea, vomiting, or diarrhoea & None reported \\
\hline $\begin{array}{l}\text { Marvez-Valls, } \\
1998\end{array}$ & Self reported side effects at follow-up call & Any adverse event & None reported \\
\hline Wei, 2002 & Self reported side effects at follow-up call & Any adverse event & $\begin{array}{l}1 \text { patient who received corticosteroids (3\%) } \\
\text { reported hiccups }\end{array}$ \\
\hline Ahn, 2003 & Not reported & Not reported & None reported \\
\hline Bulloch, 2003 & Checklist of complication at follow-up call & $\begin{array}{l}\text { Rash, joint pain, movement disorder, } \\
\text { persistent fever, or blood in urine or "cola } \\
\text { coloured" urine in past month, peritonsillar } \\
\text { abscess }\end{array}$ & None reported \\
\hline $\begin{array}{l}\text { Kiderman, } \\
2005\end{array}$ & Not reported & Any adverse event & None reported \\
\hline Olympia, 2005 & Checklist of complication at daily follow-up calls & $\begin{array}{l}\text { Headache, nausea or vomiting, abdominal } \\
\text { pain, myalgia, mood changes, dizziness, and } \\
\text { swollen legs, peritonsillar abscess }\end{array}$ & $\begin{array}{l}1 / 57(1.8 \%) \text { children in corticosteroids group } \\
\text { and } 2 / 68(2.9 \%) \text { in control group developed } \\
\text { peritonsillar abscess. } 3 / 57(5.3 \%) \text { children } \\
\text { in corticosteroid group and } 2 / 68(2.9 \%) \text { in } \\
\text { placebo group were admitted for dehydration }\end{array}$ \\
\hline Niland, 2006 & $\begin{array}{l}\text { Patient completed diaries and by structured telephone } \\
\text { interviews }\end{array}$ & $\begin{array}{l}\text { Headache, abdominal pain (Wong-Baker } \\
\text { FACES scale), fever, vomiting, and informa- } \\
\text { tion sought regarding additional medical } \\
\text { care }\end{array}$ & $\begin{array}{l}\text { Steroid treatment did not result in additional } \\
\text { patient adverse effects, symptom relapses, or } \\
\text { complications related to disease }\end{array}$ \\
\hline Tasar, 2008 & Self reported side effects at follow-up call & $\begin{array}{l}\text { Complications related to dexamethasone } \\
\text { and azithromycin }\end{array}$ & None reported \\
\hline Hayward, 2017 & $\begin{array}{l}\text { Attendance or telephone contact at any healthcare } \\
\text { facility (including GP clinic, urgent care clinic, emergency } \\
\text { department, or hospital admission) with symptoms or } \\
\text { complications associated with sore throat (defined as } \\
\text { direct suppurative complications or presentation with } \\
\text { sore throat symptoms) }\end{array}$ & Any adverse event & $\begin{array}{l}2 \text { serious adverse events (admissions for phar- } \\
\text { yngeal or peritonsillar abscess, tonsillitis, and } \\
\text { pneumonia) in corticosteroids group (0.7\%) } \\
\text { and } 3 \text { in placebo group }(1.1 \%)\end{array}$ \\
\hline
\end{tabular}

\footnotetext{
*Reflect investigators' attempts not only to detect adverse effect attributable to steroids, but also treatment failures, relapses, and complications related to disease.
} 
work. An important additional contribution of the new evidence is that it extends the applicability beyond patients with severe sore throat treated with antibiotics for group A $\beta$ haemolytic streptococcus pharyngitis in the emergency department, to a broader range of patients not treated with antibiotics.

We explored and were able to dismiss subgroup effects, with one exception: the reduction in mean time to complete resolution of pain was greater with intramuscular than with oral corticosteroids. The subgroup effect and its direction was specified a priori, the difference between subgroups was relatively large (about 21 hours), and chance seems an unlikely explanation $(\mathrm{P}<0.001)$. Credibility of the effect, however, is undermined ${ }^{34}$ as the effect modification is suggested by comparison between rather than within studies, and we found no similar difference in any other outcome. In addition, the only randomised controlled trial that compared oral and intramuscular treatment with dexamethasone reported no significant difference in any outcome. ${ }^{25}$

The few serious adverse effects in the included trials occurred with similar frequency in the intervention and control groups, although some minor adverse effects reported by patients might not always have been noted. Potential adverse effects that appear later are more likely to occur after repeated use or are rare would not have been captured in the trials. Recent observational studies have raised the possibility of extremely rare but serious adverse effects after short courses of corticosteroids. ${ }^{35}$ The quality of this evidence is, for several reasons, low with respect to the current question. The studies used observational designs from large databases with suboptimal verification of diagnoses; serious confounding by indication raises the possibility that the association is a result of the underlying disease process (such as acute inflammation or exacerbation) rather than the corticosteroids themselves; and indirectness in that the doses used in the trials were lower and the duration of treatment was considerably shorter than the duration in the observational studies. Among children, a recent overview of reviews looked at evidence from 44 randomised controlled trials on conditions that required a short course of steroids (such as asthma, bronchiolitis, croup, wheeze, and pharyngitis/ tonsillitis) and reported no major adverse events. ${ }^{36}$

Despite previous evidence that corticosteroids might be beneficial, several groups and guidelines currently recommend against their routine use on the basis that evidence was applicable only to patients with severe pharyngitis who were also prescribed antibiotics in an emergency department. ${ }^{13738}$ The body of evidence now includes a broader representation of patients. The largest and most recent randomised controlled trial included 565 patients presenting to their general practitioner rather than an emergency department, and none of the patients initially received antibiotics. ${ }^{16}$ We found no subgroup differences with respect to patient group: the evidence seems to apply equally to patients who did and did not receive antibiotics. The evidence also seems to apply equally to patients with sore throat from group A $\beta$ haemolytic streptococcus pharyngitis and some with sore throat negative for group A $\beta$ haemolytic streptococcus.

In the five trials that reported co-interventions, about $80 \%$ of the participants received additional analgesics such as paracetamol and NSAIDs. Therefore, a single dose of corticosteroids seems to further reduce pain when used in combination with other analgesics. Although the benefits are relatively small, many patients are likely to consider them important. Patients with less severe sore throat, however, will obtain less absolute benefit from corticosteroids. Thus, the balance of benefits and harms almost certainly depends on the severity of the patient's sore throat. With available evidence suggesting that serious adverse effects are rare or absent, the addition of one or two doses of steroids to the symptomatic management of sore throat is likely to appeal to many patients. More high quality data would be helpful to fully understand the net balance of benefits and harms according to severity of symptoms, particularly in primary care settings.

\section{Linked articles in this BMJ Rapid Recommendations cluster}

- Aertgeerts B, Agoritsas T, Siemieniuk RAC, et al. Corticosteroids for sore throat: a clinical practice guideline. BMJ 2017;358:j4090 doi:10.1136/bmj. j4090

summary of the results from the Rapid

Recommendation process

- Magic App (www.magicapp.org) expanded version of the results with multilayered recommendations, evidence summaries, and decision aids for use on all devices

We thank Rachel Couban, librarian at McMaster National Pain Centre Research, for her advice on the search strategies and members of the Rapid Recommendations panel for critical feedback on outcome and subgroup selection and manuscript feedbacks.

Contributors: BS and RACS contributed equally to this work. TA, RACS, POV, and GHG conceived the study idea. BS, RACS, RB-P, TA coordinated the systematic review. BS, RACS, and TA wrote the first draft of the manuscript. BS and LL designed the search strategy. BS, RACS, LL, DP, and RB-P screened abstracts and full texts. BS, RACS, RB-P, and DP acquired the data and judged risk of bias in the studies. BS performed the data analysis and is guarantor. All authors interpreted the data analysis and critically revised the manuscript.

Funding: This research received no specific grant from any funding agency in the public, commercial, or not-for-profit sectors.

Competing interests: All authors have completed the ICMJE uniform disclosure form and declare: no support from any organisation for the submitted work. RACS, AM, and GHG are members of the GRADE working group. There are no other relationships or activities that could appear to have influenced the submitted work.

Ethical approval: Not required.

Data sharing: All data are freely available within the appendices. No additional data available.

Transparency: The lead author affirms that the manuscript is an honest, accurate, and transparent account of the study being reported; that no important aspects of the study have been omitted; and that any discrepancies from the study as planned (and, if relevant, registered) have been explained.

This is an Open Access article distributed in accordance with the Creative Commons Attribution Non Commercial (CC BY-NC 4.0) license, which permits others to distribute, remix, adapt, build upon this work non-commercially, and license their derivative works on different 
terms, provided the original work is properly cited and the use is non commercial. See: http://creativecommons.org/licenses/by-nc/4.0/

1 Pelucchi C, Grigoryan L, Galeone CESCMID Sore Throat Guideline Group. Guideline for the management of acute sore throat. Clin Microbiol Infect 2012;18(Suppl 1):1-28. doi:10.1111/ j.1469-0691.2012.03766.x.

2 Principi N, Bianchini S, Baggi E, Esposito S. No evidence for the effectiveness of systemic corticosteroids in acute pharyngitis, community-acquired pneumonia and acute otitis media. Eur J Clin Microbiol Infect Dis 2013;32:151-60. doi:10.1007/s10096-012 1747-y.

3 Shaikh N, Leonard E, Martin JM. Prevalence of streptococcal pharyngitis and streptococcal carriage in children: a meta-analysis. Pediatrics 2010;126:e557-64. doi:10.1542/peds.2009-2648.

4 Herath VC, Carapetis J. Sore throat: Is it such a big deal anymore?) Infect 2015;71(Suppl 1):S101-5. doi:10.1016/j.jinf.2015.04.010.

5 Kenealy T. Sore throat. BMJ Clin Evid 2011:2011:1509.

6 Bally M, Dendukuri N, Rich B. Risk of acute myocardial infarction with NSAIDs in real world use: bayesian meta-analysis of individual patient data. BM/ 2017;357:j1909. doi:10.1136/bmj.j1909.

7 Thomas M, Del Mar C, Glasziou P. How effective are treatments othe than antibiotics for acute sore throat?Br J Gen Pract 2000;50:81720.

8 Costelloe C, Metcalfe C, Lovering A, Mant D, Hay AD. Effect of antibiotic prescribing in primary care on antimicrobial resistance in individual patients: systematic review and meta-analysis. BMJ 2010;340:c2096. doi:10.1136/bmi.c2096.

9 Spinks A, Glasziou PP, Del Mar CB. Antibiotics for sore throat. Cochrane Database Syst Rev 2013;(11):CD000023. doi:10.1002/14651858.CD000023.pub4.

10 van Driel ML, De Sutter A, Deveugele M. Are sore throat patients who hope for antibiotics actually asking for pain relief?Ann Fam Med 2006:4:494-9. doi:10.1370/afm.609.

11 Hayward G, Thompson M, Heneghan C, Perera R, Del Mar C, Glasziou P. Corticosteroids for pain relief in sore throat: systematic review and meta-analysis. BMJ 2009;339:b2976. doi:10.1136/bmj. b2976.

12 Hayward G, Thompson MJ, Perera R, Glasziou PP, Del Mar CB, Heneghan CJ. Corticosteroids as standalone or add-on treatment for sore throat. Cochrane Database Syst Rev 2012;10:CD008268. doi:10.1002/14651858.CD008268.pub2.

13 Korb K, Scherer M, Chenot JF. Steroids as adjuvant therapy for acute pharyngitis in ambulatory patients: a systematic review. Ann Fam Med 2010:8:58-63. doi:10.1370/afm.1038.

14 Wing A, Villa-Roel C, Yeh B, Eskin B, Buckingham J, Rowe BH. Effectiveness of corticosteroid treatment in acute pharyngitis: a systematic review of the literature. Acad Emerg Med 2010;17: 476-83. doi:10.1111/j.1553-2712.2010.00723.x

15 Siemieniuk RA, Agoritsas T, Macdonald H, Guyatt GH, Brandt L, Vandvik PO. Introduction to BMJ Rapid Recommendations. BM/ 2016:354:i5191. doi:10.1136/bmj.i5191.

16 Hayward GN, Hay AD, Moore MV. Effect of Oral Dexamethasone Without Immediate Antibiotics vs Placebo on Acute Sore Throat in Adults: A Randomized Clinical Trial. JAMA 2017;317:1535-43. doi:10.1001/jama.2017.3417

17 Aertgeerts B, Agoritsas T, Siemieniuk RAC. Corticosteroids for sore throat: a clinical practice guideline. BMJ 2017;358:j4090.

18 Higgins JPT, Altman DG, Gøtzsche PCCochrane Bias Methods GroupCochrane Statistical Methods Group. The Cochrane Collaboration's tool for assessing risk of bias in randomised trials. BMJ 2011;343:d5928. doi:10.1136/bmi.d5928.

19 Akl EA, Sun X, Busse JW. Specific instructions for estimating unclearly reported blinding status in randomized trials were reliable and valid. Clin Epidemiol 2012:65:262-7. doi:10.1016/j.jclinepi.2011.04.015.

20 Guyatt GH, Oxman AD, Vist GEGRADE Working Group. GRADE: an emerging consensus on rating quality of evidence and strength of recommendations. BMJ 2008;336:924-6. doi:10.1136/ bmj.39489.470347.AD
21 Altman DG, Bland JM. Interaction revisited: the difference between two estimates. BMJ 2003;326:219. doi:10.1136 bmj.326.7382.219

22 Sterne JA, Sutton AJ, Ioannidis JP. Recommendations for examining and interpreting funnel plot asymmetry in meta-analyses of randomised controlled trials. BMJ 2011;343:d4002. doi:10.1136/bmi.d4002

23 O'Brien JF, Meade JL, Falk JL. Dexamethasone as adjuvant therapy for severe acute pharyngitis. Ann Emerg Med 1993;22:212-5. doi:10.1016/S0196-0644(05)80205-7

24 Marvez-Valls EG, Ernst AA, Gray J, Johnson WD. The role of betamethasone in the treatment of acute exudative pharyngitis. Acad Emerg Med 1998;5:567-72. doi:10.1111/j.1553-2712.1998. tb02462.x

25 Wei JL, Kasperbauer JL, Weaver AL, Boggust AJ. Efficacy of singledose dexamethasone as adjuvant therapy for acute pharyngitis. Laryngoscope 2002;112:87-93. doi:10.1097/00005537200201000-00016.

26 Ahn JH, Woo WK, Kim YS. Efficacy of adjuvant short term oral steroid therapy for acute pharyngitis. Korean I Otolaryngol Head Neck Surg 2003;46:971-4.

27 Bulloch B, Kabani A, Tenenbein M. Oral dexamethasone for the treatment of pain in children with acute pharyngitis: a randomized, double-blind, placebo-controlled trial. Ann Emerg Med 2003;41: 601-8. doi:10.1067/mem.2003.136.

28 Olympia RP, Khine H, Avner JR. Effectiveness of oral dexamethasone in the treatment of moderate to severe pharyngitis in children. Arch Pediatr Adolesc Med 2005;159:278-82. doi:10.1001/ archpedi.159.3.278.

29 Niland ML, Bonsu BK, Nuss KE, Goodman DG. A pilot study of 1 versus 3 days of dexamethasone as add-on therapy in children with streptococcal pharyngitis. Pediatr Infect Dis / 2006;25:477-81. doi:10.1097/01.inf.0000219469.95772.3f.

30 Tasar A, Yanturali S, Topacoglu H, Ersoy G, Unverir P, Sarikaya S. Clinical efficacy of dexamethasone for acute exudative pharyngitis. J Emerg Med 2008;35:363-7. doi:10.1016/j.jemermed.2007.11.029.

31 Kiderman A, Yaphe J, Bregman J, Zemel T, Furst AL. Adjuvant prednisone therapy in pharyngitis: a randomised controlled trial from general practice. BrJ Gen Pract 2005;55:218-21.

32 Powell CV, Kelly AM, Williams A. Determining the minimum clinically significant difference in visual analog pain score for children. Ann Emerg Med 2001;37:28-31. doi:10.1067/mem.2001.111517.

33 Alonso-Coello P, Carrasco-Labra A, Brignardello-Petersen R. Systematic reviews experience major limitations in reporting absolute effects. J Clin Epidemiol 2016;72:16-26. doi:10.1016/j. jclinepi.2015.11.002.

34 Sun X, Briel M, Walter SD, Guyatt GH. Is a subgroup effect believable? Updating criteria to evaluate the credibility of subgroup analyses. BM/ 2010;340:c117. doi:10.1136/bmj.c117.

35 Waljee AK, Rogers MA, Lin P. Short term use of oral corticosteroids and related harms among adults in the United States: population based cohort study. BMJ 2017;357:j1415. doi:10.1136/bmj.j1415.

36 Fernandes RM, Oleszczuk M, Woods (R, Rowe BH, Cates C), Hartling L. The Cochrane Library and safety of systemic corticosteroids for acute respiratory conditions in children: an overview of reviews. Evid Based Child Health 2014;9:733-47. doi:10.1002/ebch.1980.

37 Management of sore throat and indications for tonsillectomy. A national clinical guideline. Scottish Intercollegiate Guideline Network (SIGN), April 2010. http://www.sign.ac.uk/assets/sign117.pdf

38 Shulman ST, Bisno AL, Clegg HW. Clinical practice guideline for the diagnosis and management of group A streptococcal pharyngitis: 2012 update by the Infectious Diseases Society of America. Clin Infect Dis 2012;55:1279-82. doi:10.1093/cid/cis847.

Appendix 1: Search terms and strategies Appendix 2: Summary of risk of bias assessments among the included trials Appendix 3: Supplementary tables and figure 